\title{
Pre-Service Teacher Education in Knowledge-Based Society
}

\author{
Wasant Atisabda and Sudarat Atisabda
}

\begin{abstract}
This study was to propose how to prepare the new teachers to perform their professional practices in the knowledge-based society. E-Education was announced in Thailand ICT Plan 2010 and Smart Learning was announced in the Smart Thailand Plan 2020. The faculties of education needed to develop the new teacher development program. Three models of how to teach the pre-service teachers how to use technology in teaching and learning: 1) the single educational technology course, 2) the multiple courses in educational technology, and the technology-integrated curriculum. The technology integrated curriculum was recommended in the teacher education program. All faculty members were the role models of how to implement technology in classroom and the students could learn from their professional practices. The pre-service teacher should have learned how to integrate technology innovation in teaching and learning and how to create the new learning environment. The technology standard for pre-service teacher education institution was proposed.
\end{abstract}

Index Terms-Pre-service teacher education, technology-integrated curriculum, knowledge-based society, new learning environment, smart Thailand, educational technology standard.

\section{INTRODUCTION}

Knowledge-based society refers to the society where knowledge is the primary resource for production instead of capital and labor. A knowledge-based society creates, shares, and uses knowledge for the prosperity and well-being of its people [1]. Knowledge and information are important components of the formation of a society because every society is formed by shared concepts of its people [2]. One of the contributions of globalization and new information and communication technology is the creation of a global society with shared social world knowledge and makes available to all members of the society knowledge that may be used to improve the way of people's lives. Thailand implemented two National framework for technology implementation in education: the first one was "ICT 2010 - the National Framework of Policy in Information Technology 2000-2010, which indicated Thailand vision towards the knowledge-based economy and e-education was one of keywords in this policy [3]; the second one was ICT 2020 the second National Framework of Policy in Information and Communication Technology 2010-2020, which indicated

Manuscript received March 17, 2014; revised May 25, 2014. This work was supported in part by Prince of Songkla University.

Wasant Atisabda and Sudarat Atisabda are with the Department of Educational Technology, Faculty of Education, Prince of Songkla University and Benjamarachutit School, Pattani, Thailand (e-mail: vassan.a@psu.ac.th, jsatisabda@gmail.com).
"Smart Thailand" and "Smart Learning" [4]. For this reason, it is necessary for the faculties of education all over the country to improve professional practices to be the best places to develop the new teachers to serve the new society as well as the professional development for the in-service teachers.

\section{PURPOSES OF STUdy}

1) To investigate and analyze the process of technology integration in the pre-service education program;

2) To propose a model for technology integration in teacher education;

3) To propose the technology standards for the teacher education institution.

\section{Methodology OF StUdeY}

1) General information related to technology integration in teacher education was collected from the teacher education institutions;

2) The administrators, the educational technology specialists, the faculty members and the students in the faculties of education were the key informants for the investigation;

3) The technology integration in teacher education model was analyzed and proposed.

4) The technology standards for teacher education institutions were recommended.

\section{FINDING}

\section{A. Technology Integration in Teacher Education}

There are 3 approaches for technology innovations in teacher education program: 1) a traditional approach of single instructional technology or computer-related course model, 2) a multiple technology courses model, and 3) a technology across curriculum model [5]-[7].

1) Single Technology Course Model: All faculties of education offer instructional technology course to the pre-service teachers as required professional course for the teacher preparation program as identified in Fig. 1. It also indicates that under this approach the faculty members tend to view technology as a separate type of content rather than an integral part of content area. It is also very difficult for the students to see specific ways in which technology innovation may be useful in classroom. This introductory course in technology innovations may not be sufficient to prepare the new teachers to use 
technology effectively in classroom.

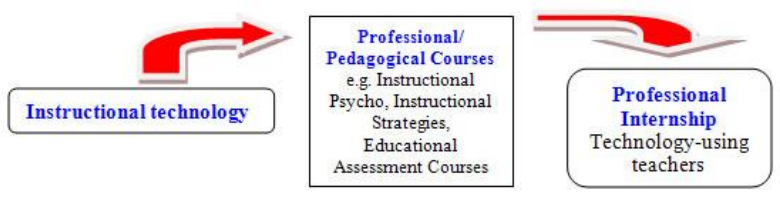

Fig. 1. Single technology course model.

2) Multiple Technology Course Model: This model is to solve the first approach by providing a series of technology-related courses as identified in Fig. 2: 1) basic technology course as a prerequisite for teaching method course, 2) teaching method courses to provide opportunities for students to develop the use of technology within the context of teaching and learning environment, and 3) advanced technology course to provide opportunities for students to develop proficiency with advanced technologies.

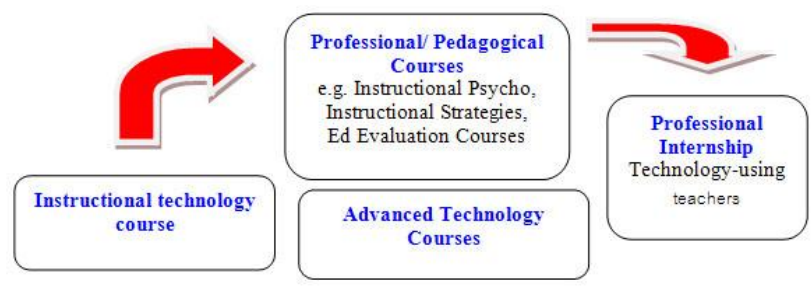

Fig. 2. Multiple technology course model.

3) Technology Integrated Curriculum Model: The faculty members have a direct influence on pre-service teachers for integrating technology innovations in their professional practices. It is important for not only the instructional faculty members but also all faculty members in professional discipline to set a model for students to see and learn how to use technologies in the real context of teaching and learning. Technology will be integrated across curriculum: in the general education courses, teaching professional courses, and professional internship as indicated in Fig. 3. The technology integrated approach is of great benefit to the new teacher students: 1) be able to enhance students' learning of content areas, 2) be able to model the behaviour that we expect students to perform.

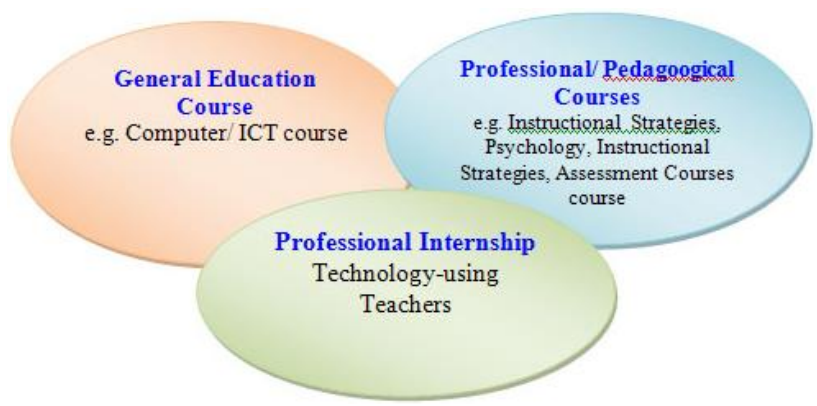

Fig. 3. Technology integrated curriculum model.

\section{B. Vision of Faculties of Education in Technology Innovation}

The faculties of education are the places to prepare teachers for the future who are able to implement technology innovations into their professional practices and to keep up with changes in the societal context. Technology innovation is dynamic by nature. Thus, new teachers need to be prepared for life-long learning skills of how continually learn technology and adapt themselves to a new learning environment in educational settings. Contemporary technologies will not be the innovation in the future anymore. Thus, the new teachers need to cope with changes in technologies and know how to implement them into educational settings.

The focus group discussion of the administrators, faculty members, educational technology specialists, and pre-service teacher students were conducted. It was identified that most of teacher education programs in Thailand implemented the first and second models of technology integration. Although most informants agreed with the innovative model of technology across curriculum, they were still concerned with curriculum and instruction management. All instructors in the faculty of education needed to learn how to integrate technology in their courses. In addition, technology facilities and infrastructure needed to be equipped to facilitate professional practices. They preferred the second model of professional practice of educational technology in teacher education and easy to put into practices, while the third model the informants indicated that it took more time to train every faculty member to use technology in teaching and training. However, when the faculty members in faculty of education were well-trained in technology innovation, the third model could be introduced to the faculty of education.

\section{Viewpoints of Stakeholders in Technology Innovations in Teacher Education}

From the four viewpoints of stakeholders including: administrators, technology innovations, faculty members, and pre-service teachers, it identified four perspectives of how to integrate technology in teacher education program.

1) Administrators' Perspectives of Technology Innovation in Implementation in Teacher Education. The external force from changes in technology along with the internal forced from new faculty members and technology innovators force the faculties of education to change and implement technology and innovations in new curriculum. The agenda for new teacher education program was set up. The internal reorganization, the restructure of teacher education program, and the budget reallocation were implemented. The encouraging and impeding conditions should have been considered to implement effectively in teacher education program. The faculty members should have been the role model of technology-using for the students and coach them how to use technology in classroom under the appropriate communication pattern and the organizational climate and culture in the faculties of education.

2) Technology Innovators' Perspectives of Technology Innovation Implementation in Teacher Education. In addition to the external forces, technology innovators needed to be the internal force to make change in teacher education program. Following the shared visions and administrators' advocacy, the major processes in technology innovation implementation will be conducted. Those were the budget reallocation and external funding supports. The requirement to restructure the teacher education curriculum to facilitate 
coaching students to be technology-using teachers was very crucial. It was also required to have the internal reorganization to support technology infrastructure facilities to faculty members and students. The most important issue was how to create organizational climate and culture to foster the implementation of technology innovations in professional practices.

3) Faculty Members' Perspectives in Technology Innovation and Implementation in Teacher Education. In addition to the restructure of teacher education curriculum and technology infrastructure, the funding for technology innovations was crucial. It was also very important to increase encouraging conditions and decrease the impeding conditions for technology-use. It was also necessary to the faculty development in technology innovations as well as the incentive system for using technology. Finally, the climate and culture in technology across curriculum should have been created to foster the new learning environment.

4) Students' Perspectives of Technology Innovation in Teacher Education. The faculty and department administrators played important roles in promoting technology integration in teacher education program. The rich technology environment and technology integrated curriculum were very crucial to develop the students to be technology-using teachers. The faculty members were the role model for students in technology use in teaching and learning. They also required the technology supports in learning and professional practices as well as the internship by being technology-use teachers.

Technology innovations were considered as teaching tools, learning tools, and classroom management tools in teacher education program. The administrators, the technology innovators, the faculty members, and the pre-service teacher students needed to learn and envision how to implement them into professional practices to make schools and classrooms more meaningful in real context of knowledge-based society.

\section{Educational Technology Standards for Teacher Education Institutions}

Based on the study of Wasant Atisabda [8] on the National Standards of Educational Technology in Teacher Education Institutions, the Faculty of Education administrators, educational technology specialist, faculty members, and pre-service teacher students as key informants for focus group discussion reconfirmed the implementation of the technology standards into professional practices. Nine Technology Standards for Teacher Education were confirmed as followings:

Standard I: Leadership in Educational Technology of the Teacher Preparation Institution. Visionary leadership in technology integration in professional practices should be developed for the pre-service and in-service teachers [9], [10].

Standard II: Teacher Education Curriculum. Technology innovation should be integrated as essential part across teacher education curriculum or technology-integrated curriculum [11].

Standard III: Technology Infrastructure in Education.
Technology infrastructure in term of software, hardware, and peopleware should be well-prepared to facilitate the modern teacher preparation program. [10], [12].

Standard IV: Contemporary Technology Innovations Fostering Instruction. Teacher education program should keep up with changes in technology innovation in education. The faculty members should teaching with technology rather than teaching about technology [9].

Standard V: Personnel in Educational Technology. Not only the educational technology specialist but also computer specialist and technical staff should be provided to facilitate pre-service teachers in professional practices [12].

Standard VI: Faculty Members' Competencies in Educational Technology. The faculty members in education discipline should be well-trained in technology integration in teacher education programs and keep up with the changes in technologies [13].

Standard VII: Instructional Model to Empower and Promote Technology Competencies for Pre-service Teachers. The faculty members should able to model how to use technology in classroom and empower teacher students to integrate technology innovations in their classroom [14].

Standard VIII: Professional Internship with Technology Integration in Professional Practices. Technology innovation should be integrated in professional internship to reflect the technology leadership. All pre-service teachers need to learn and design the instruction with modern technologies [14].

Standard IX: Competencies in Educational Technology in Professional Practices. Competencies of using contemporary technology should be identified and infuse in professional practices [8], [15]. It includes the concept of instructional technology and technology integration in professional practices.

The key informants also proposed the Guidelines for technology integration in teacher education program as followings:

1) Provide visionary leadership in technology integration in teacher education program.

2) Restructure teacher curriculum to be technology -integrated curriculum.

3) Improve technology infrastructure 11 to facilitate the faculty members and students to use technology in their professional practices.

4) Improve perspectives in technology innovation course to be "teaching with technology" rather than teaching about technology".

5) Faculty development in technology innovations in modern education settings.

\section{CONCLUSION AND DISCUSSION}

This study is to indicate another perspective of educational technology or technology innovation in education that it is not only treated as instructional media but also how to create the new learning environment to foster and empower the pre-service teachers to use technology. All pre-service teachers must be trained how to use and integrate technology innovations in order to become the visionary technology-using teachers with competency to create the new 
learning environment. The teacher preparation institution should be facilitated with technology facilities to train the new teachers to teach in the knowledge-based society.

\section{REFERENCES}

[1] B. Samuthjak, "Network-based society: the world after knowledge-based," Productivity World 41, July-August 2009.

[2] D. Todose. (2008). Education management in knowledge based society. [Online]. Available: http://search.proquest.com/docview/1097684368? accountid=28431

[3] National Electronics and Computer Technology Center, Policy framework in information technology of Thailand from 2001-2010, NECTEC, Bangkok, 2002.

[4] National Electronics and Computer Technology Center, Policy framework in information technology of Thailand from 2011-2020, NECTEC, Bangkok, 2010

[5] W. Atisabda, "Pre-service teacher education in the information society: a qualitative case study of instructional efforts and faculty implementation of technology innovation," Ph.D. dissertation, University of Missouri-Columbia., 2001.

[6] W. Atisabda, "Faculty of Education in the information society: new direction for quality assurance in technology innovation in teacher education program in the U.S.," Journal of Education, vol. 14, no. 1, pp. 15-27, 2002.

[7] W. Atisabda, "Technology integration in teacher education," Journal of Education, vol. 14, no.1, pp. 1-13, 2003.

[8] W. Atisabda, "The development of national standards of educational technology for teacher education institution," Songklanakarin Journal of Social Sciences and Humanities, vol. 12, no.4, pp. 455-482, 2006.

[9] V. C. X. Wang, Technology and its impact on educational leadership: innovation and change, Harshey, PA: IGI Global, 2012.

[10] V. E. Gerland and C. Tadeja, Educational Leadership and technology: Preparing school administrators for a digital age, New York: Routledge, 2013.

[11] S. Frei, A. Gammill, and S. Iron, Integration technology into the curriculum, Huntington Beach, CA: Shell Education, 2007.

[12] J. Wedman, "Building technology infrastructure and enterprises in a college of education: increasing performance capacity," Education Technology, 1998.

[13] A. Gill and B. Dalgano, "Influences on pre-service teachers" preparedness to use ICTs in the classroom," Proceedings Ascilite Melbourne 2008, 2008

[14] G. Watson and S. Prestridge, "Changing patterns of pre-service teachers' ICT competencies and what it means for pre-service teacher education programs," presented at the AARE Conference Fremantle 2001.

[15] E. M. Willis and P. Raine, "Technology and the Changing Face of Teacher Preparation," Contemporary Issues in Technology and Teacher Education, vol. 1, no. 3, pp. 412-420, 2001.

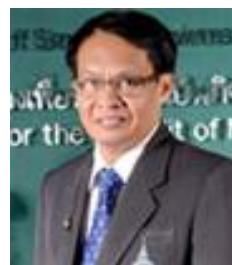

Missouri, USA.

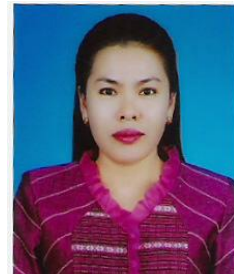

Wasant Atisabda is an assistant professor at the Department of Educational Technology, Faculty of Education, Prince of Songkla University, Thailand. $\mathrm{He}$ received a bachelor of education majoring in teaching german as the second language and master of education in field of audio-visual education from Chulalongkorn University, Thailand. He got Ph.D. in higher and continuing education from University of

Sudarat Atisabda is a school teacher at the Department of Foreign Languages, Benjamarachutit Pattani School, Thailand. She received a bachelor of education in English from Prince of Songkla University, Thailand, master of education in reading education, and educational specialist in reading education from University of Missouri, USA. 